\title{
CORRELATO
}

\section{TRATAMIENTO DE LA TOXICOSIS}

\author{
DrS. FERNANDO MARTINEZ, WERNER BUSTAMANTE y \\ OTTO GRUNEWALDT
}

\author{
Cátedra de Pediatria del Prof. Anibal Arizria.
}

Hospital "Luis Calvo Mackenna", Santiago.

Esta contribución al tema de las Diarreas en la Infania de este VII Congreso Nacional de Pediatría se refiere a una breve exposición del tratamiento de la Toxicosis que hemos venido efectuando cje una manera uniforme, con pequeñas variaciones en relación con las adquisiciones progresivas, desde el punto de vista de de la hidratación y aporte de electrolitos y con el agregado de sulfonamidos y/o antibióticos a medida de su aparición.

Comprende un total de 1.014 casos internados en el Hospital Luis Calvo Mackenna entre los años 1943 y 1955 , debiendo cumplir todos ellos, para ser incluídos en esta casuística, con los requisitos o fundamentos de diagnóstico que se exponer en el Cuadro No 1.

\section{CUADRO No 1}

Fundamentos de diagnóstico de Toxlcosis en el materia revisado.

1.-Compromiso psico semsorlal;

2.-Dlarrea aguda, (vomitos);

4.-Deshidratacion. (escleredema);

4.-Acidosis:

5.-Colapso circuletorio;

6.-Infeccion enteral o paraenteral.

En todos los casos el tratamiento se hizo siguiendo una pauta uniforme que puede verse en el Cuadro $\mathrm{N}^{\circ} 2$.

Creemos de interés recordar que el lavado gástrico no sólo tiene su indicación sobre los vómitos si no también como un medio de eliminar valencias ácidas que se eliminan por el estómago y además de productos tóxicos en él acumulados.

En cuanto al agua de manzanilla usada en la dieta hídrica, ella contiene según determinaciones efectuadas en nuestro laboratorio los siguientes valores en M. Eq./lt.: Sodio 3,6. Potasio 0,82. Calcio 4 .
CUADRO Ne 2

Tratimiento

1. LaYedo gastrico:

2. Dleta hidrica: 24 horas.

A) Blatratación oral:

Abua de manzenlla; (eventualmente con Rtr-

B) Hudratación paraenteras. ger en partes jguales).

in) Solución Ringer-Clucosa

b) Golucjón 3-2-1: Glucosado-Fislohogico-Hartman.

c) Soluclón Darrow.

3. Dlets hidratante:

Suero de Eledón-Agus de arroz en partes igualet con $6 \%$ Dextro-Maltosa.

1.er dia: 50 gr, p/kg. peso,

$2^{0}$ dla: 100 " ", ",

Rerlimentacion curativa:

50-100 gr. de Eledon $5 \%$ al cuarto dia, auraentando progresivamente.

5. Bulfonamidos y/o antibioticos a las dosls habituales. 6. Medidas generales $y$ gintomiticas,

Respecto a la vía de hidratación preferimos la oral, dejando la paraenteral para aquellos casos en que por los vómitos pertinaces o las condiciones generales del enfermo no es posible usar la primera.

En atención a que el período de administración de la llamada Dieta hidrante se prolonga tres días, estimamos conveniente hacer un análisis comparativo de su contenido en electrolitos lo que se efectuó en 15 muestras de agua de arroz $y$ de suero de Eledón, mediante el fotómetro de llama, obteniendo los resultados expuestos en el Cuadro $\mathrm{N}$ ?

\section{CUADRO N\$ 3}

Aporte de EJectrolitos.

\begin{tabular}{|c|c|c|c|}
\hline & $\begin{array}{l}\text { Valores } \\
\text { Sodio }\end{array}$ & $\begin{array}{c}\text { aproxjmados en } \\
\text { Potasio }\end{array}$ & $\underset{\text { Calcio }}{\operatorname{mpq} / 1 \mathrm{t} .}$ \\
\hline $\begin{array}{l}\text { Suero de Eledon } \\
\text { agua de arroz } \\
\text { Suero Finger } \\
\text { Ringer Lactato } \\
\text { Solucion Darrow }\end{array}$ & $\begin{array}{r}30 \\
10 \\
148 \\
131 \\
122\end{array}$ & $\begin{array}{r}37 \\
2 \\
4 \\
4 \\
35\end{array}$ & $\begin{array}{r}40 \\
20 \\
6 \\
4 \\
0\end{array}$ \\
\hline
\end{tabular}


Podemos ver como comparado con los sueros Ringer, Ringer-Lactato y Darrow: el Suero de Eledón contiene valores en Potasio que son muy aproximados a los que se encuentran en la Solución Darrow y muy superíores a los de los otros dos, como también sucede con el Calcio, siendo el Sodio inferior a los otros tres.

Ahora bien como el Suero de Eledón se administra en partes iguales con agua de arroz nos encontramos que la mezcla hidratante a base de lo que hemos dado en llamar liquidos nutritivos, proporciona un aporte bastante adecuado de electrolitos, excepto el sodio, cuyo contenido es bajo. Además, es posible que dado el aporte de calcio más alto que el de los otros 3 sueros, no se haya observado en nuestro hospital el sindrome post-acidótico con hipocalcemia que se ha descrito como observado después de las 24 horas de tratamiento.

Una vez iniciada la realimentación curativa se aumenta progresivamente $\mathrm{y}$ así a los 15 días de tratamiento aproximadamente el setenta por ciento de nuestros enfermos están recibiendo una ración calórica de cien calorias por kilógramos de peso.

En lo que se refiere a sulfonamidos, usamos de preferencia aquellos de acción enteral: sulfaguanidina, succinilsufatiazol, ftalilsulfacetamida $\quad 0,10 \mathrm{gr} . \mathrm{p} / \mathrm{kg}$. dosis inicial, 0,05 gr. p. $/ \mathrm{kg}$. cada 4 horas a continuación). Etreptomicina oral 500 mgr. diarios en 5 tomas. Cloramfenicol 50 mgrs. por $\mathrm{kg}$. peso en 24 horas. En menor proporción se empleó los derivados de las ciclinas y la penicilina sólo cuando alguna infección paraenteral lo justificaba.

Respecto a medidas generales y sintomáticas se refieren especialmente a combatir el shock mediante las transfusiones de plasma : 10 a $30 \mathrm{cc}$. por $\mathrm{kg}$.) o de sangre cuando había anemia, ambas siempre después de plazos variables después de iniciada la hidratación mediante fleboclisis con los sueros mencionados efectuada con un ritmo no superior a 15 gotas por minuto vigilando cuidadosamente la diuresis.

En el gráfico siguiente están expuestas las incidencias y la letalidad de esta casuística. El aumento de las hospitalizaciones en los dos últimos años (1954 y 1955 ), más que un aumento real de la enfermedad creemos se debe a la mayor demanda

\section{TOXKCOSS HOSPITALIZAOAS PORCENTAJE OE MORTALIOAO POR ANOOS}

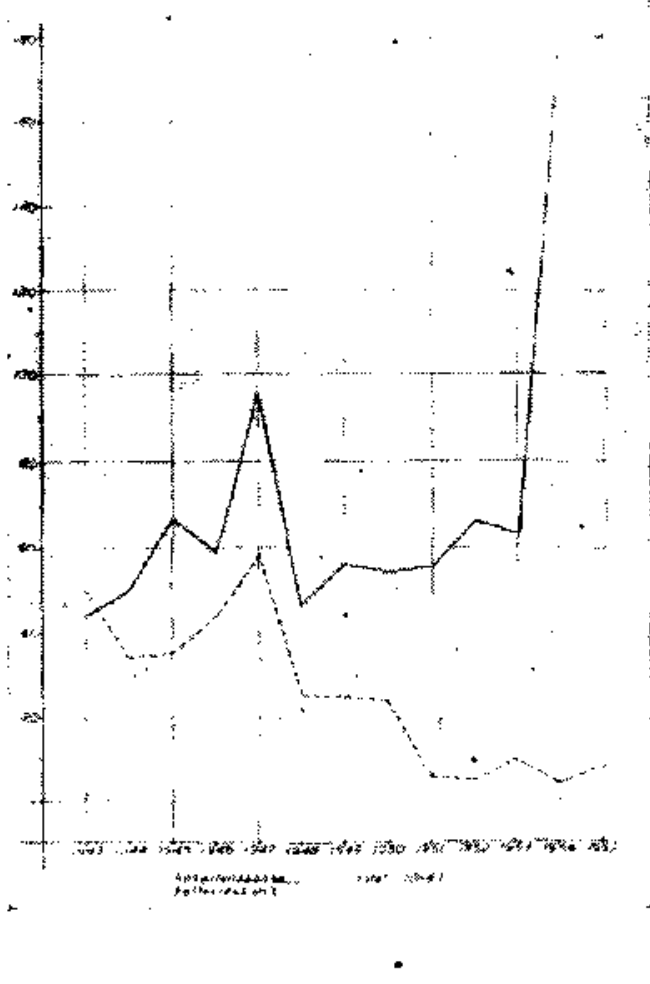

de consultas desde la fusión de los servicios asistenciales: a las mayores posibilidades de atención y de capacidad del hospital mediante la ampliación de los servicios de lactantes y especialmente al Servicio de atención semi-ambulatoria o de "media-hospitalización" que se ensayó por primera vez en nuestro medio en el Hospital Calvo Mackenna el año 1949. En él se proporciona en forma precoz el mismo tratamiento durante el día, para ser enviado el enfermo a su casa durante la noche, si el estado lo permite, para volver al dia siguiente o permaneciendo en él si sus condiciones son desfavorables.

Puede verse en el grafíco coma mediante todo el conjunto de medidas, ha sido posible bajar la mortalidad de un $50 \%$ a un promedio de 6,4\%. para los últimos cinco años.

Analizada separadamente, dado su mayor nứmero, la casuística de 1954 y de 1955 comprobamos las características expuestas en el Cuadro $N^{0} 4$. 
CUADRO NP 4

CASUISTICA 1954-55

\begin{tabular}{|c|c|c|c|}
\hline Hosp1tallzatos: 358 & & Fallecidos & $22 \quad(6,1 ; ?$ \\
\hline $\begin{array}{l}\text { Edad en meses } \\
\text { mAs de } 5 \text { a } 12 \\
\text { mảs de } 12 \text { a } 24\end{array}$ & & $\begin{array}{l}\text { italizados } \\
211 \\
133 \\
14\end{array}$ & $\begin{array}{c}\text { Faltechados } \\
17 \\
5 \\
0\end{array}$ \\
\hline $\begin{array}{l}\text { verano } \\
\text { Otoño } \\
\text { Invierno } \\
\text { Primavera }\end{array}$ & Total & $\begin{array}{r}358 \\
93 \\
36 \\
20 \\
209\end{array}$ & $\begin{array}{r}23 \\
6 \\
1 \\
0 \\
15\end{array}$ \\
\hline $\begin{array}{l}\text { Eutrofla } \\
\text { Distrot } 1 \text { it } \\
\text { Alrofla }\end{array}$ & Tutal & $\begin{array}{r}358 \\
29 \\
216 \\
13\end{array}$ & $\begin{array}{r}22 \\
1 \\
15 \\
6\end{array}$ \\
\hline & Total & 358 & 22 \\
\hline
\end{tabular}

Predominó la toxicosis en los menores de 5 meses, siendo la mayoría de ellos desnutridos $(91 \%)$ y de ellos. 13 atróficos. La mayor incidencia estacional fué en (') - mavera y luego en verano.

\section{CONCLUSIONES}

1) Entre los años 1943 y 1955 se ha logrado bajar la mortalidad de las toxicosis internadas en el Hospital Calvo Mackenna de $50^{\prime} ;$ a un promedio de $6,4^{\prime} ;$ para los últimos 5 años । 1951-55).

2) Como factores causales de esta disminución se consideran: a) Tratamiento precoz y hospitalización oportuna, hechos logrados en parte a través de un Servicio semi-ambulatorio de tratamiento con gran aumento de las hospitalizaciones en los dos últimos años (1954-55).

b) Empleo de medidas de hidratación y dieta hidratante con aporte electrolítico que permite prolongar la hipoalimentación sin dañar al enfermo cuyo estado nutritivo siempre es deficiente.

c) Uso de sulfonamidos y/o antibióticos según la observación clínica y los datos suministrados por la bacteriología.

3 ) Por la gran mayoría de distrofias que constituyen este material se considera fundamentalmente como medida profiláctíca el tratamiento del trastorno nutritivo crónico.

4) Dado el gran predominio de la toxicosis en los meses de Primavera y a continuación Verano, se estima conveniente una conducta dietética preventiva durante esa época y abstención de otras causas que puedan provocarla: calor, abrigo excesivo, infecciones, vacunas, etc.

5) Toda medida preventiva debe extremarse en el primer semestre de la vida. época en que predomina la toxicosis en los niños alimentados artificialmente. 